\title{
SISTEM INFORMASI PENYUSUNAN JADWAL MATA PELAJARAN MENGGUNAKAN METODE ANT COLONY PADA SEKOLAH MENENGAH KEJURUAN SWASTA MAITREYAWIRA TANJUNGPINANG
}

Susanto, Moch.Rizki Romdoni

Email : Susanto@yahoo.com, rizki@sttindonesia.ac.id

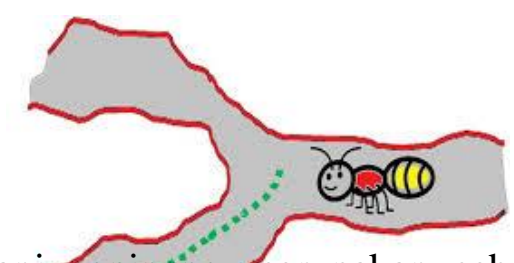

Sekolah Menengah Kejuruan Swasta Maitreyawira Tanjtngpinang merupakan sebuah lembaga yang bergerak di dalam bidang pendidikan. Pada Sekolah Menengah Kejuruan Swasta Maitreyawira Tanjungpinang terdapat penyusunan jadwal mata pelajaran yang masih menggunakan cara manual dan memakan waktu yang cukup lama ketika pihak waka kurikulum melakukan sebuah penyusunan jadwal .

Dengan alasan di atas maka penulis mencoba untuk membuat suatu sistem informasi penyusunan jadwal mata pelajaran menggunakan metode ant colony yang terkomputerisasi dengan tempat penyimpanan database yang terstruktur, sehingga nantinya dapat membantu Sekolah Menengah Kejuruan Swasta Maitreyawira Tanjungpinang dalam penyusunan jadwal mata pelajaran yang efektif dan efisien.

Penyusunan jadwal mata pelajaran pada Sekolah Menengah Kejuruan Swasta Maitreyawira Tanjungpinang diimplementasikan berdasarkan analisis kebutuhan dengan menggunakan bahasa pemrograman Borland Delphi 7 dan basis datanya menggunakan Microsoft Accsess 2007. Sistem Informasi Penyusunan Jadwal Mata Pelajaran Menggunakan Metode Ant Colony pada Sekolah Menengah Kejuruan Swasta Maitreyawira Tanjungpinang ini merupakan sistem untuk membantu pihak waka kurikulum Sekolah Menengah Kejuruan Swasta Maitreyawira Tanjungpinang dalam melakukan proses penyusunan jadwal mata pelajaran.

Kata kunci : Sistem Informasi,Mata Pelajaran,Metode Ant Colony

\section{Pendahuluan}

Jadwal mata pelajaran merupakan hal yang penting dalam proses belajar-mengajar. Setiap jurusan pada sekolah memiliki jadwal mata pelajaran yang disusun sedimikian rupa untuk menjaga berlangsungnya proses belajar-mengajar di jurusan tersebut. Jadwal mata pelajaran yang baik memiliki distribusi mata pelajaran yang merata setiap harinya untuk setiap tingkatnya tanpa mengalami kendala dalam proses belajar-mengajar.

Dalam penyusunan jadwal mata pelajaran bukanlah pekerjaan yang mudah. Ada beberapa faktor yang mempengaruhi dalam penyusunan jadwal mata pelajaran yaitu guru, dan ruangan. Setiap faktor tersebut memiliki keadaan yang dapat menjadi sumber masalah dalam penyusunan jadwal mata pelajaran.

Misalnya masalah yang dihadapi dari faktor guru adalah terjadinya bentrok pada saat guru mengajar di dua lokasi yang berbeda dalam waktu yang sama. Sedangkan dari faktor ruangan misalnya terjadi bentrok pada ruangan yang sedang berlangsung proses ngajar mengajar.. 
Untuk mengatasi masalah-masalah di atas, dapat dilakukan dengan cara komputerisasi dengan membangun sebuah sistem informasi penyusunan jadwal mata pelajaran. Sistem akan menerima semua masalah tersebut sebagai masalah terstruktur untuk menghasilkan solusi penjadwalan mata pelajaran yang baik. Masalah terstruktur merupakan masalah yang dimungkinkan untuk menggunakan metode atau peraturan mengenai penyusunan agar masalah dapat diidentifikasi atau dipahami. Dengan penggunaan metode atau peraturan tersebut, dimungkinkan pula melakukan identifikasi pemecahan pengganti dan mengevaluasinya, serta menentukan pemecahan yang terbaik .

Dalam penjadwalan mata pelajaran, masalah yang dihadapi merupakan masalah kompleks yang diselesaikan secara rutin atau berulang-ulang. Masalah kompleksnya dapat dilihat dari setiap faktor dalam penyusunan jadwal mata pelajaran yang saling berhubungan dengan faktor lainnya.

Dari persoalan diatas, penulis mencoba membahas pemecahannya dalam bentuk Laporan Skripsi dengan judul "SISTEM INFORMASI PENYUSUNAN JADWAL MATA PELAJARAN MENGGUNAKAN METODE ANT COLONY PADA SEKOLAH MENENGAH KEJURUAN SWASTA MAITREYAWIRA TANJUNGPINANG”.

\section{Kajian Pustaka}

\subsection{Algoritma Ant Colony}

Algoritma Semut (Ant Colony) merupakan algoritma yang dimunculkan sebagai suatu pendekatan multi-agen terhadap optimasi berbagai permasalahan yang berkaitan dengan graf (Paninalone, 2011). Sampai saat ini, berbagai upaya pengembangan dilakukan untuk memperluas pemanfaatan dari algoritma semut. Berbagai pemanfaatan yang sudah umum digunakan antara lain untuk menyelesaikan permasalahan rute kendaraan, penyurutan sekuensial, pewarnaan graf, permasalahan routing pada jaringan dan berbagai permanfaatan lainnya

Munurut Fernandez (2012) cara kerja algoritma semut sebagai berikut :

1. Pada Awalnya, semut keliling dengan acak.

2. Ketika semut - semut menemukan jalur yang berbeda misalnya sapai pada persimpangan, mereka akan mulai menentukan arah jalan secara acak seperti Gambar 1.a

3. Sebagian semut memilih berjalan ke atas dan sebagian lagi akan memilih berjalan ke bawah seperti Gambar 1.b 
4. Ketika menemukan makanan mereka kembali ke koloninya sambil memberikan tanda dengan jejak feromon.

5. Karena jalur yang ditempuh lewat jalur bawah lebih pendek, maka semut yang bawah akan tiba lebih dulu dengan asumsi kecepatan semua semut adalah sama seperti Gambar 1.c

6. Feromon yang ditinggalkan oleh semut di jalur yang lebih pendek aromanya akan lebih kuat dibandingkan feromon di jalur yang lebih panjang seperti Gambar 1.d

7. Semut - semut lain akan lebih tertarik menyikuti jalur bawah karena aroma feromon lebih kuat.

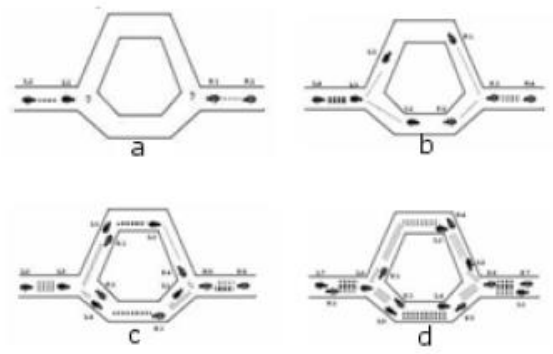

Gambar 1 Tingkah laku semut

(Sumber : Fernandez, 2012)

Menurut Muttakhiroh dkk. (2007) dalam algoritma semut diperlukan variable dan langkah -langkah untuk menentukan jarak terpendek, yaitu :

Langkah 1 :

Inisialisasi harga parameter - parameter algoritma.

Parameter - parameter yang di inisialisasikan adalah :

1. Intensitas jejak semut antar kota dan perubahannya ( $\tau_{-}$ij)

2. Banyak kota (n) termasuk kordinat $(\mathrm{x}, \mathrm{y})$ atau jarak antar kota (d_ij)

3. Kota berangkat dan kota tujuan

4. Tetapan siklus - semut (Q)

5. Tetapan pengendali intensitas jejak semut $(\alpha)$, nilai $\alpha \geq 0$

6. Tetapan pengendali visibilitas $(\beta)$, nilai $\beta \geq 0$

7. Visibilitas antar kota $=1 / d_{-}$ij $\quad(\eta$ ij $)$

8. Banyak Semut (m)

9. Tetapan penguapan jejak semut $(\rho)$, nilai pharus $>0$ dan $<1$ untuk mencegah jejak pheromone tak terhingga. 
10. Jumlah siklus maksimum ([NC)_max) bersifat tetap selama algoritma dijalankan, sedangkan $\tau$ _ij akan selalu diperbahrui harganya pada setiap siklus algoritma mulai dari sklus pertama $(\mathrm{NC}=1)$ sampai tercapai jumlah siklus maksimum $\left(\mathrm{NC}=\left[\mathrm{NC} \rrbracket \_\max \right)\right.$ atau sampai terjadi konvergensi.

Inisialisasi kota pertama setiap semut.

Setelah inisialisasi $\tau$ ij dilakukan, kemudian m semut ditempatkan pada kota pertama tertentu secara acak.

Langkah 2 :

Pengisian kota pertama ke dalam tabu list. Hasil inisialisasi kota pertama setiap semut dalam langkah 2 harus diisikan sebagai elemen pertama tabu list. Hasil dari langkah ini adalah terisinya elemen pertama tabu list setiap semut dengan indeks kota tertentu, yang berarti bahwa $\operatorname{tabuk(1)}$ bisa berisi indeks kota antara 1 sampai $n$ sebagaimana hasil inisialisasi pada langkah 2.

Langkah 3 :

Penyusunan rute kunjungan setiap semut ke setiap kota. Koloni semut sudah terdistribusi ke sejumlah atau setiap kota, akan mulai melakukan perjalanan dari kota pertama masing - masing sebagai kota asal dan salah satu kota - kota lainnya sebagai kota tujuan. Kemudian dari kota kedua masing - masing, koloni semut akan melanjutkan perjalanan dengan memilih salah satu dari kota - kota yang tidak terdapat pada tabukJika s menyataka indeks urutan kunjungan, kota asal dinyatakan sebagai tabuk(s) dan kota - kota lainnya dinyatakan sebagai $\{\mathrm{N}$-tabuk\}, maka untuk menentukan kota tujuan digunakan persamaan probabilitas kota untuk dikunjungi sebagai berikut :

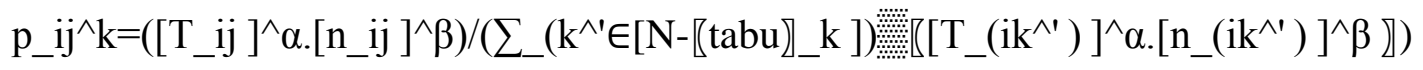
untuk $\mathrm{j} \in\left\{\mathrm{N}-[\mathrm{tabu}] \_\mathrm{k}\right\}$

Dan

$\mathrm{p} \_\mathrm{ij} \wedge \mathrm{k}=0$ untuk j lainnya $\quad(2.2)$

Dengan i sebagai indeks kota asal dan j sebagai indeks kota tujuan. Stelah mendapatkan nilai probalitas yang ingin dikunjungi maka langkah selanjut nya adalah mencari nilai kumulatid dengan persamaan

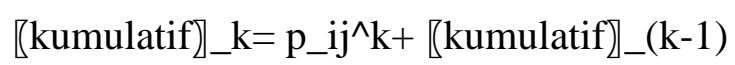


Setalah mendapatkan nilai kumulatif langkah selanjut nya adalah mengambil nilai random dari kumulatif1sampai dengan kumulatifn untuk mencari kota tujuan yang akan dikunjungi selanjutnya oleh semut.

Langkah 4 :

Perhitungan panjang rute setiap semut.

Perhitungan panjang rute tertutup (length closed tour)atau Lk setiap semut dilakukan setelah satu siklus diselesaikan oleh semua semut. Perhitungan ini dilakukan berdasarkan tabuk masung - masing dengan persamaan berikut :

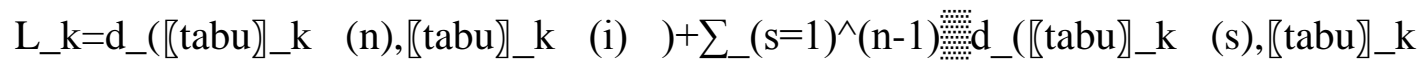
$(\mathrm{s}+1))$

Dengan d_ij adalah jarak antara kota I ke kota j yang dihitung berdasarkan persamaan :

$$
\left.d_{-} i j=\sqrt{ }\left(\llbracket\left(x \_i-x_{-} j\right)\right) \rrbracket^{\wedge} 2+\llbracket\left(y \_i-y_{-} j\right) \rrbracket^{\wedge} 2\right)
$$

Pencarian rute terpendek.

Setelah Lk setiap semut dihitung, akan didapat harga minimal panjang rute tertutup setiap siklus atau LminNC dan harga minimal panjang rute tertutup secara keseluruhan adalah atau Lmin

Perhitungan perubahan harga intensitas jejak kaki semut antar kota. Koloni semut akan meninggalkan jejak - jejak kaki pada lintasan antar kota yang dilaluinya. Adanya penguapan dan perbedaan jumlah semut yang lewat,menyebabkan kemungkinan terjadinya perubahan harga intensitas jejak kaki semut antar kota. Persamaan perubahan ini adalah :

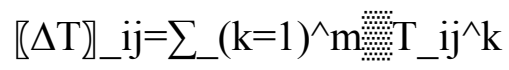
)

Dengan $\Delta \tau_{-} \mathrm{ij}^{\wedge} \mathrm{k}$ adalah perubahan harga intensitas jejak kaki semut antar kota setiap semut yang dihitung berdasarkan persamaan :

$\llbracket \Delta \mathrm{T} \rrbracket\left[\mathrm{ij}{ }^{\wedge} \mathrm{k}=\mathrm{Q} / \mathrm{L} \_\mathrm{k}\right.$, untuk $(\mathrm{i}, \mathrm{j}) \in$ kota asal dan kota tujuan dalam \tabu】_k (2.7)

$\llbracket \Delta \mathrm{T} \rrbracket \_\mathrm{ij}{ }^{\wedge} \mathrm{k}=0$, untuk $(\mathrm{i}, \mathrm{j})$ lainnya $(2.8)$

Langkah 5 :

Perhitungan harga intensitas jejak kaki semut antar kota untuk siklus selanjutnya. Harga intensitas jejak kaki semut antar kota pada semua lintasan antar kota ada kemungkinan berubah karena adanya penguapan dan perbedaan jumlah semut yang melewati. Untuk siklus selanjutnya, semut yang akan melewati lintasan tersebut harga 
intensitasnya telah berubah. Harga intensitas jejak kaki semut antar kota untuk siklus selanjutnya dihitung dengan persamaan :

$$
T_{-} \mathrm{ij}=\rho . T \_i j+\llbracket \Delta \mathrm{T} \rrbracket \_\mathrm{ij}
$$

Atur ulang harga perubahan intensitas jejak kaki semut antar kota.

Untuk siklus selanjutnya perubahan harga intensitas jejak semut antar kota perlu diatur kembali agar memiliki nilai sama dengan nol

Langkah 6 :

Pengosongan tabu list, dan ulangi langkah 2 jika diperlukan, Tabu list perlu dikosongkan untuk diisi lagi dengan urutan kota yang baru pada siklus selanjutnya, jika jumlah siklus maksimum belum tercapai atau belum terjadi konvergensi, Algoritma diulang lagi dari langkah 2 dengan harga parameter intensitas jejak kaki semut antar kota yang sudah diperbaharui.

\section{Analisis Sistem}

Tahap analisis perancangan metode Ant Colony meliputi langkah-langkah mengenai variabel Ant Colony, parameter - parameter Ant Colony, pengisian jadwal kedalam Tabu List, menyusun rute kunjungan dengan perhitungan probalitas antar jadwal, perhitungan error, perhitungan harga itensitas semut antar guru, pengosongan Tabu List, . Berikut penjelasan lebih lanjut dari masing - masing tahapan.

\subsubsection{Variabel Metode Ant Colony}

Dalam Algoritma Semut terdapat 2 variabel yaitu variabel input dan variabel output.

1) Variabel Input

1. Data Jumlah Jam Per-Mata Pelajaran

2. Data Slot Time

3. Data Guru

4. Data Kelas

2) Variabel Output

1. Jadwal Mata Pelajaran

\subsubsection{Parameter - parameter Algoritma Semut}

Pada Tahap Pertama Adalah Menetukan Parameter - parameter pada Algoritma Semut, Berikut adalah parameter - parameter Algoritma Semut: 
1. Alpha $(\alpha)$ dan Beta $(\beta)$ adalah koefisien yang digunakan untuk perhitungan probabilitas.

2. Rho $(\rho)$ dan Tetapan Siklus Semut (Q) adalah koefisien yang digunakan untuk perhitungan feromon

3. Alpha $(\alpha)=$ Semakin besar nilai alpha, semakin besar nilai probabilitas.

4. Beta $(\beta)=$ Semakin besar nilai beta, semakin kecil nilai probabilitas

5. Rho $(\rho)=$ Semakin besar nilai rho, semakin kecil nilai feromon

6. Tetapan Siklus Semut $(\mathrm{Q})=$ Semakin besar nilai beta, semakin besar nilai feromon

7. Intensitas jejak semut antar kota dan perubahannya $\left(\tau_{i j}\right)$ awal $=0.01$

8. Maksimum Siklus $\left(\mathrm{NC}_{\max }\right)=$ Jumlah iterasi yang harus dilakukan semut

9. Iterasi $=$ Jumlah Putaran

10. Banyak Semut $=$ Banyak Slot Time

11. Jumlah Kota $=$ Banyak Slot Time

12. Jarak antar slot time $\left(\mathrm{d}_{\mathrm{ij}}\right)=1$

13. Visibilitas antar slot time $\left(\eta_{i j}\right)=1 / \mathrm{d}_{\mathrm{ij}}$

Tabel 1 Data Parameter Algoritma Semut

\begin{tabular}{|l|l|}
\hline Alpha & 1.0 \\
\hline Beta & 1.0 \\
\hline Rho & 0.5 \\
\hline $\mathrm{Q}$ & 1.0 \\
\hline $\mathrm{NC}_{\max }$ & 1 \\
\hline Jumlah Slot & 8 \\
\hline Jumlah Semut & 8 \\
\hline
\end{tabular}

Tabel 2 Pelajaran SMK Maitreyawira Kelas X Akuntansi 1 dan 2

\begin{tabular}{|c|c|c|r|c|}
\hline NO & Pelajaran & $\begin{array}{r}\text { Gmlh } \\
\text { Jam }\end{array}$ & $\begin{array}{r}\text { Slot } \\
\text { Time }\end{array}$ \\
\hline 1 & Agama Buddha & Yanto & $\begin{array}{r}2 \\
\text { Jam }\end{array}$ & AG \\
\hline 2 & $\begin{array}{c}\text { Pend. } \\
\text { Kewarganegaraan }\end{array}$ & $\begin{array}{c}\text { Angga Ivanna Christy, } \\
\text { S.Ap }\end{array}$ & $\begin{array}{r}2 \\
\text { Jam }\end{array}$ & PKN \\
\hline 3 & B. Indonesia & $\begin{array}{c}\text { Siti Nafsiyah, S.Pd } \\
2 \\
\text { Jam }\end{array}$ & IND \\
\hline 4 & Kewirausahaan & Emfriyanthi S., SE & $\begin{array}{r}2 \\
\text { Jam }\end{array}$ & KWU \\
\hline \multicolumn{2}{|c|}{ Total } & \multicolumn{2}{|c|}{ Jam } \\
\hline
\end{tabular}




\begin{tabular}{|c|c|c|c|}
\hline \multirow{2}{*}{ NO } & \multirow{2}{*}{ WAKTU } & \multicolumn{2}{|c|}{$\begin{array}{lllll}K & E & L & A & S\end{array}$} \\
\hline & & X АKT 1 & X АKT 2 \\
\hline 1 & $07.45-08.30$ & \multicolumn{2}{|c|}{ UPACARA BENDERA } \\
\hline 2 & 08.30-09.15 & \multirow{2}{*}{$1 a$} & \multirow{2}{*}{$1 b$} \\
\hline 3 & 09.15-10.00 & & \\
\hline 4 & $10.00-10.25$ & \multicolumn{2}{|c|}{ ISTIRAHAT 1} \\
\hline 5 & $10.25-11.10$ & \multirow{2}{*}{$2 a$} & \multirow{2}{*}{$2 b$} \\
\hline 6 & $11.10-11.55$ & & \\
\hline 7 & $11.55-12.40$ & $3 a$ & $3 b$ \\
\hline 8 & $12.40-13.05$ & \multicolumn{2}{|c|}{ ISTIRAHAT 2} \\
\hline 9 & $13.05-13.50$ & 3a & $3 b$ \\
\hline 10 & $13.50-14.35$ & \multirow{2}{*}{$4 a$} & \multirow{2}{*}{$4 b$} \\
\hline 11 & $14.35-15.20$ & & \\
\hline
\end{tabular}

Gambar 2 Slot Time Kelas X Akutansi 1 dan 2

\subsubsection{Menyusun Rute Kunjungan}

Penyusunan rute kunjungan setiap semut ke setiap slot. Koloni semut sudah terdistribusi ke sejumlah atau setiap slot, akan mulai melakukan perjalanan dari slot pertama masing - masing sebagai slot asal dan salah satu slot lainnya sebagai slot tujuan. Kemudian dari slot kedua masing - masing, koloni semut akan melanjutkan perjalanan dengan memilih salah satu dari slot - slot yang tidak terdapat pada $t a b u_{k}$ Jika $s$ menyatakan indeks urutan kunjungan, slot asal dinyatakan sebagai $\operatorname{tabu}_{k}(s)$ dan slot - slot lainnya dinyatakan sebagai $\{N$-tabuk $\}$, maka untuk menentukan slot tujuan digunakan persamaan probabilitas berikut

$$
p_{i j}^{k}=\frac{\left[T_{i j}\right]^{\alpha} \cdot\left[n_{i j}\right]^{\beta}}{\sum_{k^{\prime} \in\left[N-t a b u_{k}\right]}\left[T_{i k^{\prime}}\right]^{\alpha} \cdot\left[n_{i k^{\prime}}\right]^{\beta}} \text { untuk } j \in\left\{N-\operatorname{tabu}_{k}\right\}
$$




\section{Perancangan Sistem}

Flowchart merupakan diagram yang menggambarkan alur kerja dari system yang dibangun.

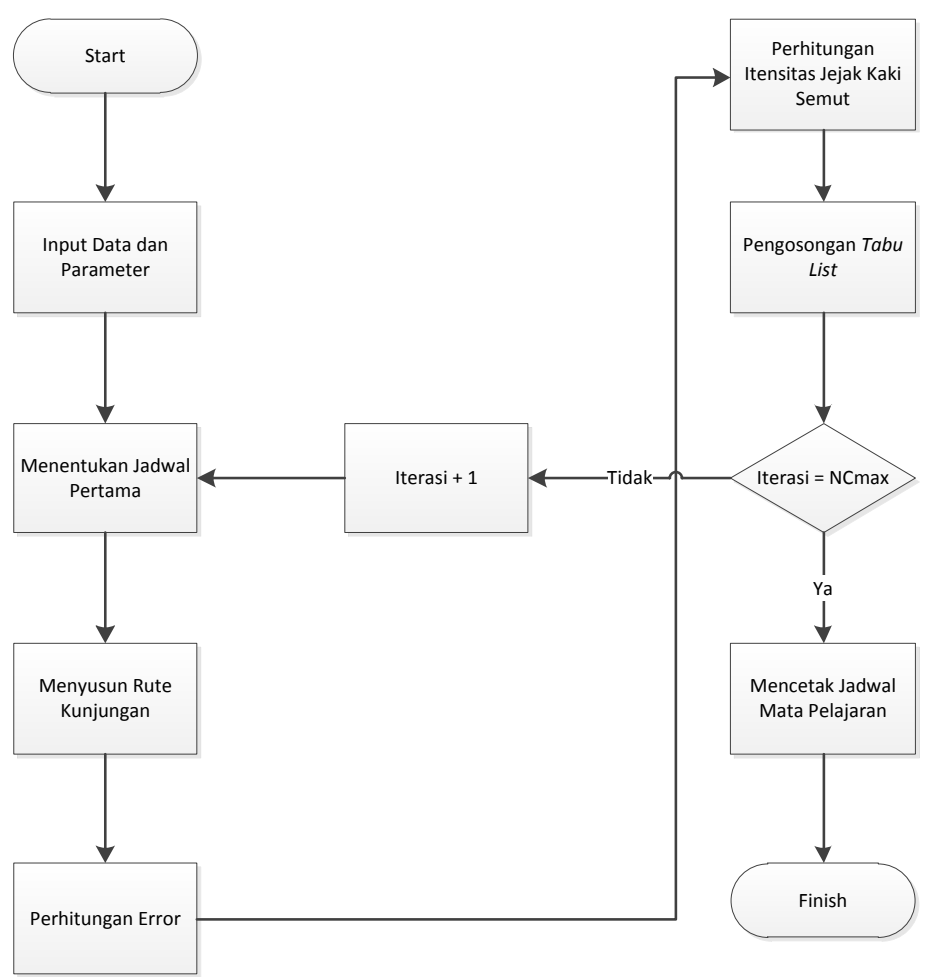

Gambar 3 Flowchart Sistem

\subsection{Diagram Konteks}

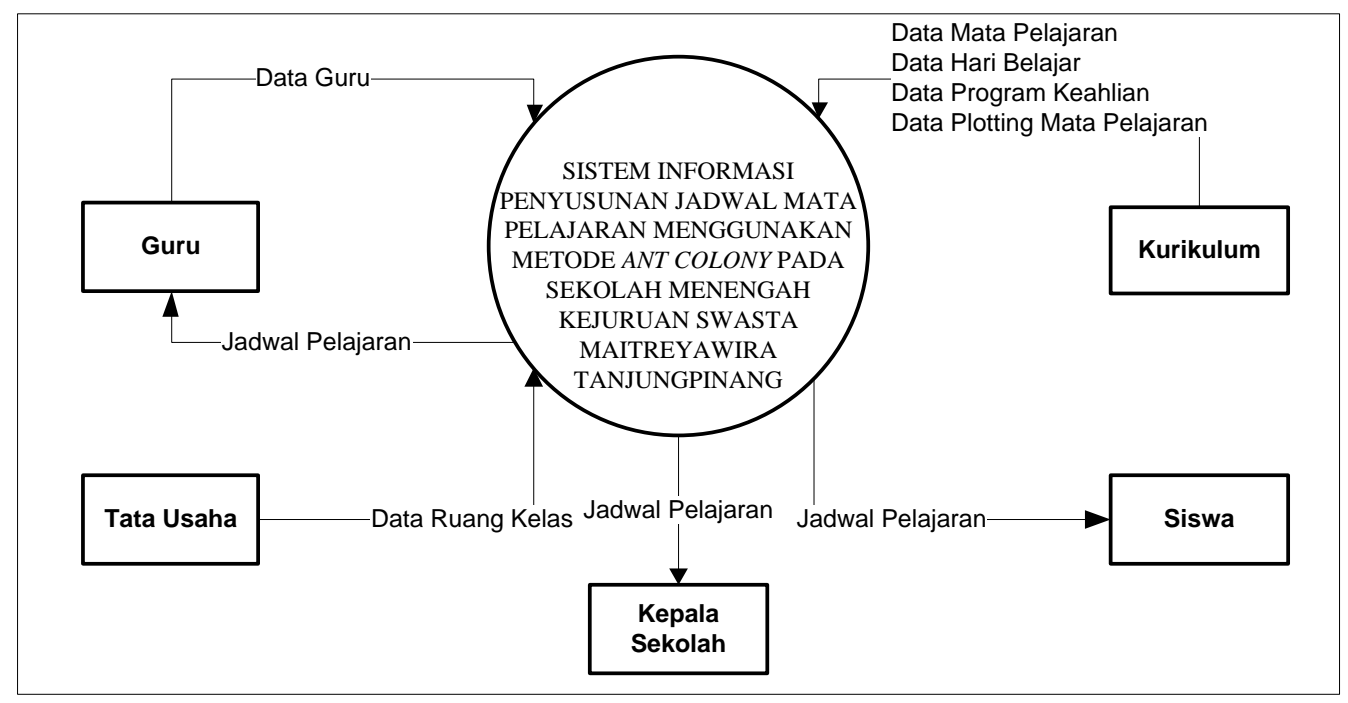

Gambar 4 Diagram Konteks 


\subsection{DFD}

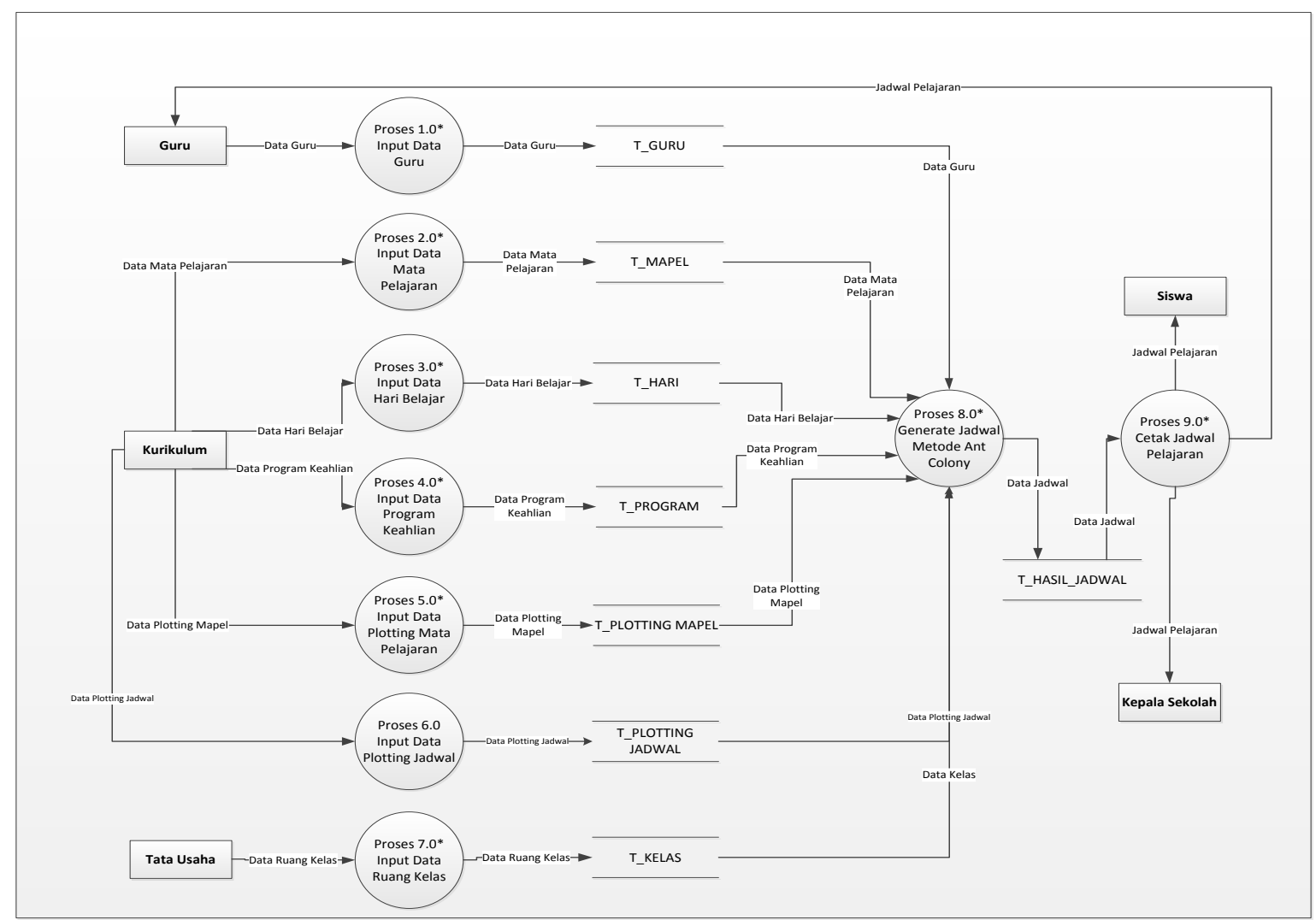

Gambar 5 DFD

\section{Implementasi Sistem}

\subsection{Kebutuhan Perangkat Lunak}

Untuk mendukung sistem informasi penyusunan jadwal mata pelajaran menggunakan metode ant colony ini dibutuhkan perangkat lunak untuk menjalankan sistem tersebut yaitu:

1. Sistem Operasi Windows 7

2. Borland Delphi 7

3. Microsoft Access 2007 


\subsection{Kebutuhan Perangkat Keras}

Untuk mendukung sistem informasi penyusunan jadwal mata pelajaran menggunakan metode ant colony, selain dibutuhkan perangkat lunak, juga memerlukan perangkat keras untuk menjalankan sistem ini.

Perangkat keras yang minimal diperlukan untuk sistem informasi penyusunan jadwal mata pelajaran menggunakan metode ant colonysesuai dengan rekomendasi yang diberikan Microsoft Access adalah sebagai berikut :

1. CPU Intel Pentium $®(2.40 \mathrm{GHz}, 2 \mathrm{~Gb}$ of RAM $)$

2. Harddisk terpasang minimal $80 \mathrm{~Gb}$

3. Mouse dan Keyboard

4. Monitor

5. Printer

\subsection{Pengujian Sistem}

Pengujian dilakukan untuk memastikan apakah semua fungsi sistem bekerja dengan baik dan mencari kesalahan yang mungkin terjadi pada aplikasi. Tujuan utama dilakukan pengujian ialah untuk menilai apakah sistem yang dirancang telah sesuai dengan apa yang diharapkan.

Pendekatan yang dilakukan dalam pengujian software ini yaitu menggunakanpendekatan black box testing. Pendekatan ini melakukan pengujian denganmemfokuskan pada kebutuhan fungsional dari software.

\section{Penutup}

\subsection{Kesimpulan}

Berdasarkan hasil penelitian yang telah dilakukan oleh penulis pada Sekolah Menengah Kejuruan Swasta Maitreyawira Tanjungpinang dimana penyusunan jadwal mata pelajaran disana masih disusun secara manual. Untuk mempermudah dalam penyusunan jadwal mata pelajaran tersebut, penulis merancang sebuah sistem informasi penyusunan jadwal mata pelajaran menggunakan metode ant colony yang akan mempermudah waka kurikulum dalam penyusunan jadwal mata pelajaran yang terjadi pada sekolah itu. Dari hasil penelitian tersebut, maka dapat diambil kesimpulan sebagai berikut: 
1. Penyusunan jadwal mata pelajaran menjadi lebih sistematis.

2. Memudahkan waka kurikulum dalam penyusunan jadwal mata pelajaran agar tidak terjadi proses revisi secara berulang kali.

\subsection{Saran}

Untuk pengembangan lebih lanjut agar mendapatkan sistem informasi yang lebih baik dan memiliki tingkat pemanfaatan yang lebih tinggi untuk mencapai tujuan yang diinginkan, maka penulis menyarankan untuk :

1. Untuk pengembangan sistem penyusunan jadwal menggunakan metode Ant Colony dapat di kembangkan ke dalam sistem yang berbasiskan web.

2. Melakukan perbandingan dengan menggunakan metode lainnya agar dapat memperoleh hasil yang lebih baik dalam proses penyusunan jadwal mata pelajaran , contohnya seperti penyusunan jadwal mata pelajaran menggunakan metode genetik.

\section{DAFTAR PUSTAKA}

Anonim. Panduan Penulisan Laporan Kerja Praktek dan Tugas Akhir, STTI, 2014, Tanjungpinang.

Nugroho, Adi. Analisis dan Perancangan Sistem Informasi dengan Metodologi| Berorientasi Objek.

N. Candra Apriyanto "Sistem Informasi Penjualan Arloji Berbasis WEB pada CV Sinar Terang Semarang", 2011

Bambang Wahyudi S.Kom MMSi, “ Konsep Sistem Informasi dari BIT sampai ke Database”, 2007

N. Candra Apriyanto "Sistem Infromasi Penjualan Arloji Berbasis WEB pada CV Sinar Terang Semarang", 2011

Muhammad Ibnu Naufal "Sistem Informasi Akuntansi Penerimaan Kas pada BMT Bintaro", 2011

Henny Hendarti "Perancangan Sistem Informasi Registrasi dan Keanggotaan Klub", 2009

Linda Marlinda,S.kom, Sistem Basis Data, Andi [2004, Yogyakarta]

Edhy Sutanta, Basis Data dalam Tinjauan Konseptual, CV.Andi Offset (2011, Yogyakarta)

Ir. Harianto Kristanto, Konsep dan Perancangan Database, Andi (2004, Yogyakarta)

Kani dkk, Pemprograman Database Menggunakan Delphi , Graha Ilmu (2010, Yogyakarta)

Fernandez, A., 2012, Pembangunan Aplikasi Penyusunan Jadwal Kuliah Menggunakan Algortima Semut, Skripsi, Universitas Diponegoro, Semarang.

http://id.wikipedia.org/wiki/Microsoft_Access 2007 [ 17 September 2015, 15.40 WIB ] 